$6^{\text {th }}$ INTERNATIONAL ATLANTIC ECONOMIC CONFERENCE

New York, U.S.A., October 6-9, 2005

\title{
The Influence of Fiscal Policy on Economic Growth
}

\author{
Professor Moisa ALTAR,
}

Doctoral School of Finance and Banking, Academy of Economic Studies, 6

Piata Romana, sect. 1, Bucharest, Romania

e-mail: maltar@ase.ro; maltar@starnets.ro

http://www.dofin.ase.ro

phone: +40-744-529831

fax: $+40-21-3129549$

and

Professor Judita SAMUEL

Romanian - American University, Bucharest, 1, Bd. Expozitiei, sect. 1, Bucharest, Romania

e-mail: jsamuel@csm.ro

phone: +40-723-371036

JEL Clasification : C 61, D 99,E 31, E 41, E 62, E 63, H 62, H 63, O 41. Macro focus 


\begin{abstract}
In this paper we analyze the influence of several types of fiscal policies on the process of economic growth, namely on the rate of growth of consumption.

We formulate and analyze two types of economic growth models. The first refers to the way in which a consumer-producer agent takes decisions when the elements concerning fiscal policy are exogenous. The second model is a global model including the economic agent, as well as the government.

Both models are dynamic models with discrete variables on infinite horizon. The technique used is provided by the Maximum Principle.

We perform a comparative analysis of the results obtained on the basis of the two models. What is surprising is the conclusion that the growth rate of consumption is larger for the second model. At the same time, we prove that if the ratio between private and public consumption is equal to the ratio between the elasticity coefficients of the utility function, then the rate of economic growth does not depend on the value of the tax rate.
\end{abstract}

\title{
1. Introduction
}

Public finances affect growth in several ways. In the theoretical literature that links public finances with growth, three expenditure variables have been considered: public investment spending, public consumption spending and social welfare or redistributive spending. Some of this literature has also considered public spending that increases human capital and spending that contributes to innovation , such as that for research and development as core spending, as it enhances the human capital base (investment) and technological progress. Total government spending average about 45\% of GDP in industrialized countries, but the range from $30 \%$ of GDP to $60 \%$ suggests great differences across countries ( European Commission, AMECO, as quoted in Tanzi and Schuknecht (2003)).

There is some governmental activity and related public spending that is essential for the performance of the economy. This "core", or "essential", or "productive" spending may as important to growth as private capital and labour. This core spending can directly raise the human and physical capital stock and technical progress in the economy , but it can do so also indirectly, by creating synergies for private activities. The level of this spending depends on how efficient the government is in using the resources available. The more efficient is the government, the lower needs to be the spending level. But government spending also depends on a number of "exogenous" factors: geography, the level of development of the country and on the sophistication of its markets (Tanzi (2004)). 
Core spending includes spending for essential administrative services and justice, basic research, basic education and health, public infrastructure, internal and external security. Spending on these categories, in industrialized countries, represents , on average, about $20 \%$ of GDP or $45 \%$ of total public expenditure (cfr. European Commission, AMECO database).

Public spending on education ( via human capital) and research and development ( innovation/technical progress) enhances growth. As the new growth theory suggests, public activity is needed as it can compensate for market failure due to networkexternalities, non-linearities and monopolistic competition. Public spending (e.g. in the areas of education and $R \& D$ ) can drive education and $R \& D$ to a more efficient level than would prevail in a pure market scenario.

Public investment is a narrower concept than productive or core spending. It is more specifically directed to the creation of physical infrastructure. Normally gross fixed capital formation is limited to around 2-3\% of GDP (or about 5\% of total spending). Obviously, public investment may contribute to growth. Apart from directly raising an economy's capital stock, it is often argued that public investment on infrastructure is necessary to crowd in private investment and to reduce some private costs.

An important aspect of endogenous growth theory over the years has been the study of how fiscal variables, both on the expenditure and revenue sides, affect the long-run growth rate of an economy. On the expenditure side, Barro (1990) shows how the presence of productive public services, as an input in the production function, can affect the steady-state growth. This paper considers the flow of public services rather than the stock of public capital. Futagami, Morita and Shibata (1993) consider the latter, and demonstrate the existence of a unique steady growth equilibrium with private and public capital. They also analyze the transitional dynamics of their model. Departing from the balanced budget set-up of the above-cited papers, Bruce and Turnovsky (1999), considering an array of fiscal instruments, identify the conditions under which a tax cut can improve the long-run government budget balance.

One of the novel features of the endogenous growth literature is that it emphasizes the importance of fiscal policy as a determinant of long-run economic growth. In this context, the role of public capital has been investigated at both theoretical and empirical levels. Thus, following the early work by Arrow and Kurz (1970), Futagami et al. (1993) introduce public capital as a pure public good, along with private capital, but now within an endogenous growth framework. Greiner and Semmler (2000) develop an endogenous growth model with public capital and government debt. Their aim is to investigate the long-run effects of public investment policies under different budgetary regimes, which are versions of the so-called golden rule of public finance.

This is a budgetary regime which postulates that a government is allowed to run a budget deficit as long as this is used to finance increases in the public capital stock. Greiner and Semmler consider different modifications (based on alternative definitions of the budget deficit) to the "golden rule" and derive the important result that the growth effects of an increase in public investment depend on the exact budgetary regime within which the government operates. In particular, they demonstrate that less strict budgetary regimes do not necessary imply higher rates of long-run growth.

In the paper "Fiscal and Monetary Policies and Economic Growth" (2003), M. Altar and J. Samuel analyze the way in which monetary and fiscal policy influence the 
performances of economic growth. The analysis is made on the basis of a dynamic model with discrete variables of the Sidrauski- Brock type, with infinite-lived households and money in the utility function. The model is with a representative private agent and a government sector consisting of a consolidated fiscal authority and central bank. Households receive an exogenous perishable endowment each period, decide about consumption and pay net real lump-sum tax.

The state variable of the model is government debt, and the decision variables are: consumption and the amount of money detained by the agent.

The optimality conditions are obtained by using the Maximum Principle for discrete dynamic systems.

In the paper "Fiscal Policy, Public Capital and Economic Growth" (2004), M. Altar and J. Samuel analyze a model in which, following W.H. Fischer and S.J.Turnovsky (1998), the public good is treated as a durable capital good, subject to congestion. The analysis is made on the basis of a dynamic model with discrete variables. The optimality conditions for the representative agent's problem are deduced on the basis of the Maximum Principle for discrete dynamic systems (Altar, 1976).

The production function considered within the model is a function of three variables: labour, stock of private capital and services obtained from the stock of public capital. A critical feature of the model concerns the specification of the productive services derived by the representative agent from public capital. Several variants for this function are analyzed in the paper.

\section{The Decentralized Outcome}

We assume that the economy consists of $N$ identical agents. The utility function of the representative producer-consumer agent is of the form:

$U(C, S)=\frac{1}{1-v}\left(C^{1-\gamma} S^{\gamma}\right)^{1-v}$

It is a utility function of Bernoulli type, depending on two variables, namely $c$ - per capita private consumption

and

$s$ - government supplied public good (public goods per capita).

The production function of the individual agent is:

$$
f(k, g)=A k^{\alpha} g^{\beta}
$$

where $k$ represents the private capital stock , and $g$ represents the productive services desired by the representative agent from government capital (public capital stock). With the above notations, the model of the representative agent is: 


$$
\begin{aligned}
& \sum_{t=0}^{\infty} \delta^{t} U\left(C_{t}, S_{t}\right) \\
& k_{t+1}=(1-\mu) k_{t}+I_{t} \\
& b_{t+1}=\left[1+(1-\tau) r_{t}\right] b_{t}+(1-\tau) f\left(k_{t}, g_{t}\right)-C_{t}-I_{t} \\
& b_{t+1} \geq 0
\end{aligned}
$$

where $b$ denotes government bonds, $\tau$ is the tax rate and $r$ is the interest rate. We denoted by $I$ investment, by $\delta$ - the rate of time preference, and by $\mu$ - the coefficient of wear and tear of capital.

We assume that, for each time period t, the values of $s, g$ and $\tau$ are given exogenously. In order to derive the optimal solution of the model (3)-(6), we apply the Maximum Principle for dynamic systems with discrete variables [ ]. The Hamiltonian function of the system is:

$$
H=\delta^{t} U\left(C_{t}, S_{t}\right)+\psi_{t}^{1}\left[(1-\mu) k_{t}+I_{t}\right]+\psi_{t}^{2}\left\{\left[1+(1-\tau) r_{t}\right] b_{t}+(1-\tau) f\left(k_{t}, g_{t}\right)-C_{t}-I_{t}\right\}
$$

We denoted by $\psi_{1}$ and $\psi_{2}$ the dual variables, and by $\lambda$ - the Lagrange type multiplier corresponding to constraint (6).

The optimality conditions are:

$\delta^{t} U_{1}^{\prime}\left(C_{t}, S_{t}\right)=\psi_{t}^{2}+\lambda_{t}(8)$

$\psi_{t}^{1}=\psi_{t}^{2}+\lambda_{t}$

Moreover, for the Lagrange multiplier, the Maximum Principle provides the following information:

$\lambda_{t} \cdot b_{t+1}=0$

The dynamic equations for the dual variables are:

$\psi_{t-1}^{1}=(1-\mu) \psi_{t}^{1}+(1-\tau) f_{1}^{\prime}\left(k_{t}, g_{t}\right)\left(\psi_{t}^{2}+\lambda_{t}\right)$

$\psi_{t-1}^{2}=\left[1+(1-\tau) r_{t}\right]\left(\psi_{t}^{2}+\lambda_{t}\right)$

We assume that $b_{t}>0, b_{t+1}>0$ (13)

i.e. that the stock of government bonds is positive in periods $t$ and $t+1$.

According to the information provided by the Maximum principle, we have $\lambda_{t-1}=0$ and $\lambda_{t}=0$.

From equation (9) it follows that

$\psi_{t}^{1}=\psi_{t}^{2}, \psi_{t-1}^{1}=\psi_{t-1}^{2}$ 
Consequently, equations (10) and (11) become

$\psi_{t-1}^{1}=\left[1-\mu+(1-\tau) f_{1}^{\prime}\left(k_{t}, g_{t}\right)\right] \psi_{t}^{1}$

$\psi_{t-1}^{1}=\left[1+(1-\tau) r_{t}\right] \psi_{t}^{1}\left(11^{\prime}\right)$

Comparing (10') and (11'), we obtain the equality

$1-\mu+(1-\tau) f_{1}^{\prime}\left(k_{t}, g_{t}\right)=1+(1-\tau) r_{t}$

or

$r_{t}=f_{1}^{\prime}\left(k_{t}, g_{t}\right)-\frac{\mu}{1-\tau}$

Formula (15) gives the optimal value of the interest rate expected by the representative agent.

It follows that

$r_{t}=r_{t}\left(\tau, \mu, k_{t}, g_{t}\right)$

The following relations point out the behavior of the optimal interest rate with respect to the main variables of the model

$\frac{\partial r_{t}}{\partial \tau}>0 ; \frac{\partial r_{t}}{\partial k_{t}}<0 ; \frac{\partial r_{t}}{\partial g_{t}}>0 ; \frac{\partial r_{t}}{\partial \mu}<0$

From (17) it can be seen that the optimal interest rate increases as the tax rate increases. At the same time, the optimal interest rate increases as the stock of public capital, as well as the coefficient of wear and tear increase.

In what follows, we assume that $b_{t}>0$, which means that $\lambda_{t}=0$.

From (9) it follows that

$\psi_{t}^{1}=\psi_{t}^{2}=\psi, \forall t$

We denote:

$q_{t}=\frac{\psi_{t}}{\delta_{t}}$

The optimality condition (8) becomes:

$U_{1}^{\prime}\left(C_{t}, S_{t}\right)=q_{t}(20)$

and the dynamic equation of the new variable is: 
$q_{t-1}=\left[\delta(1-\mu)+(1-\tau) f_{1}^{\prime}\left(k_{t}, g_{t}\right)\right] q_{t}$

Taking into account the form (1) of the utility function, from relations (20) and (21) we obtain:

$C_{t-1}^{(1-\gamma)(1-v)-1} S_{t-1}^{\gamma(1-v)}=\left[\delta(1-\mu)+(1-\tau) f_{1}^{\prime}\left(k_{t}, g_{t}\right)\right] C_{t}^{(1-\gamma)(1-v)-1} S_{t}^{\gamma(1-v)}$

The growth rate of private consumption is given by

$$
\frac{C_{t}}{C_{t-1}}=\left[\delta(1-\mu)+(1-\tau) f_{1}^{\prime}\left(k_{t}, g_{t}\right)\right] \frac{1}{1-(1-\gamma)(1-v)}\left(\frac{S_{t}}{S_{t-1}}\right)^{-\frac{\gamma(1-v)}{1-(1-\gamma)(1-v)}}
$$

Formula (23) points out that the growth rate of private consumption is a decreasing function of the parameter $\tau$ (tax rate). Also, the growth rate of private consumption depends decreasingly on the growth rate of public consumption $\left(\frac{s_{t}}{s_{t-1}}\right)$.

In what follows, we assume a balanced growth process, in the sense that the growth rate of private consumption equals the growth rate of public consumption, i.e.

$$
\frac{C_{t}}{C_{t-1}}=\frac{S_{t}}{S_{t-1}} \text {, for any t. }
$$

In this case, formula (23) becomes

$$
\frac{C_{t}}{C_{t-1}}=\frac{S_{t}}{S_{t-1}}=\left[\delta(1-\mu)+(1-\tau) f_{1}^{\prime}\left(k_{t}, g_{t}\right)\right]^{\frac{1}{v}}
$$

\section{The problem of dynamic equilibrium in the case of Decentralized Outcome}

The dynamic equilibrium for the producer-consumer agent is described by the following three equations

$$
\left\{\begin{array}{l}
k_{t+1}=(1-\mu) k_{t}+I_{t} \\
b_{t+1}=\left[1-\mu+(1-\tau) f_{1}^{\prime}\left(k_{t}, g_{t}\right)\right] b_{t}+(1-\tau) f\left(k_{t}, g_{t}\right)-c_{t}-I_{t} \\
c_{t}=\left[\delta(1-\mu)+(1-\tau) f_{1}^{\prime}\left(k_{t}, g_{t}\right)\right] \frac{1}{v} c_{t-1}
\end{array}\right.
$$

The dynamic model described by equations (25)-(27) contains two exogenous variables, namely $g_{t}$ and $\tau$; the first one can vary in time.

In order to derive some meaningful conclusions concerning equilibrium, we make the additional assumption that the ratio between the stock of public capital and the stock of private capital is constant, i.e. 


$$
\frac{g_{t}}{k_{t}}=\theta
$$

For convenience, we denote

$$
f\left(k_{t}, g_{t}\right)=f\left(k_{t}, \theta k_{t}\right)=\varphi\left(k_{t}, \theta\right)
$$

With the above notation, system (25)-(27) can be rewritten as

$$
\left\{\begin{array}{l}
k_{t+1}=(1-\mu) k_{t}+I_{t} \\
b_{t+1}=\left[1-\mu+(1-\tau) \varphi^{\prime}\left(k_{t}, \theta\right)\right] b_{t}+(1-\tau) \varphi\left(k_{t}, \theta\right)-c_{t}-I_{t} \\
c_{t}=\left[\delta(1-\mu)+(1-\tau) \varphi^{\prime}\left(k_{t}, \theta\right)\right] \frac{1}{v} c_{t-1}
\end{array}\right.
$$

We recall that equations (26) and (26'), respectively, were obtained from equation (5), by using for the interest rate $r_{t}$ its optimal value given by (15).

The precise nature of the steady-state equilibrium occurs when:

$k_{t+1}=k_{t}=k^{*} ; b_{t+1}=b_{t}=b^{*} ; c_{t}=c_{t-1}=c^{*}$

and consists of the following relationships:

$$
\left\{\begin{array}{l}
I^{*}=\mu k^{*} \\
(1-\tau) \varphi^{\prime}\left(k^{*}, \theta\right)=\frac{1}{\delta}-(1-\mu) \\
b^{*}=\frac{1}{1 / \delta-1}\left[c^{*}+I^{*}-(1-\tau) \varphi\left(k^{*}, \theta\right)\right]
\end{array}\right.
$$

Taking into account the form (2) of the production function, it follows

$$
\begin{aligned}
& \varphi(k, \theta)=A \theta^{\beta} k^{\alpha+\beta} \\
& \varphi^{\prime}(k, \beta)=A \alpha \theta^{\beta} k^{\alpha+\beta-1}
\end{aligned}
$$

From equation (32) we obtain

$$
k^{*}=\left[\frac{1}{(1-\tau) A \alpha \theta^{\beta}}\left[\frac{1}{\delta}-(1-\mu)\right]\right]^{\frac{1}{\alpha+\beta}}
$$

and , from (33) we obtain 
$b^{*}=\frac{1}{1 / \delta-1}\left[C^{*}+\mu k^{*}-(1-\tau) A \theta^{\beta}\left(k^{*}\right)^{\alpha+\beta}\right]$

Relationship (37) points out the fact that the equilibrium value $c^{*}$ of consumption and that of government bonds, $b^{*}$, cannot be determined independently.

If we assume that, in steady state, $b^{*}=0$, from relationship (37) we obtain

$$
c^{*}=(1-\tau) A \theta^{\beta}\left(k^{*}\right)^{\alpha+\beta}-\mu k^{*}
$$

where the value of $k^{*}$ is given by (36).

We also have to take into account the equilibrium of public budget, namely

$\tau \varphi\left(k^{*}, \theta\right)=s^{*}+h^{*}$

Denoting

$$
\frac{C^{*}}{S^{*}}=\varepsilon \quad(40),
$$

relationship (39) becomes

$$
\begin{aligned}
& \tau \varphi\left(k^{*}, \theta\right)=\frac{1}{\varepsilon} c^{*}+\theta \mu k^{*}, \text { or } \\
& \tau \varphi\left(k^{*}, \theta\right)=\frac{1}{\varepsilon}\left[(1-\tau) \varphi\left(k^{*}, \theta\right)-\mu k^{*}\right]+\theta \mu k^{*}
\end{aligned}
$$

From (41) it follows that the level of tax rate compatible with the steady - state is

$$
\hat{\tau}=\frac{1}{1+\varepsilon}+\frac{\varepsilon \theta-\mu}{1+\varepsilon} \frac{k^{*}}{\varphi\left(k^{*}, \theta\right)}
$$

In this situation, from equation (38) it follows that the steady-state value of consumption will be

$$
c^{*}=\frac{1}{1+\varepsilon}\left[\varphi\left(k^{*}, \theta\right)-\varepsilon(\theta+\mu) k^{*}\right]
$$

Equation (43) shows that the equilibrium value of consumption of the agent depend essentially on the parameters $\varepsilon$ and $\theta$.

\section{The benevolent government's problem}


In the previous section, where we analyzed the problem of the producer agent, we assumed initially that the public capital stock, $g$, government expenditures, $s$, public investment, $h$, as well as the tax rate, $\tau$ represent variables which are exogenous with respect to the agent. Only in the last part of that section was the public budget balance taken into account.

In this section, we have a global approach, taking into account the decisions needed to be taken by the economic agent, as well as those implying the government.

As concerns the tax rate, this will remain exogenous to the model, but the results obtained will allow simulation of several alternatives, corresponding to different tax rates. The general model is described by equations (44)-(48).

$$
\begin{aligned}
& \sum_{0}^{\infty} \delta^{t} U\left(c_{t}, s_{t}\right) \\
& k_{t+1}=(1-\mu) k_{t}+I_{t} \\
& g_{t+1}=(1-\mu) g_{t}+h_{t} \\
& b_{t+1}=\left[1+(1-\tau) r_{t}\right] b_{t}-\tau f\left(k_{t}, g_{t}\right)+h_{t}+S_{t} \\
& f\left(k_{t}, g_{t}\right)-C_{t}-I_{t}-h_{t}-S_{t} \geq 0
\end{aligned}
$$

As can be seen from formula (44), we have in view a benevolent government: the "performance" of the model represents maximization of the cumulated utility of economic agents' consumption over the horizon under consideration (maximization of welfare).

The model (44-48) contains three state variables, namely the private capital stock, $k$, public capital stock, $g$, and the public debt, $b$. As concerns the decision variables, there are four of them, namely two referring to the consumer-producer agent ( $c$ and $I$ ), and two referring to government decisions ( $s$ and $h$ ).

Equations (45)-(47) describe the dynamics of the state variables, and inequation (48) refers to the general macroeconomic equilibrium. As can be seen from (48), the macroeconomic equilibrium refers to a closed economy.

The Hamiltonian function of the system is

$$
\begin{aligned}
H_{t}= & \delta^{t} U\left(C_{t}, S_{t}\right)+\psi_{t}^{1}\left[(1-\mu) k_{t}+I_{t}\right]+\psi_{t}^{2}\left[(1-\mu) g_{t}+h_{t}\right]+\psi_{t}^{3}\left\{\left[1+(1-\tau) r_{t}\right] b_{t}-\tau f\left(k_{t}, g_{t}\right)+h_{t}+S_{t}\right\}+ \\
& \lambda_{t}\left[f\left(k_{t}, g_{t}\right)-C_{t}-I_{t}-h_{t}-S_{t}\right]
\end{aligned}
$$

Applying the Maximum Principle, we obtain the following necessary optimality conditions: 


$$
\left\{\begin{array}{l}
\delta^{t} U_{1}^{\prime}-\lambda_{t}=0 \\
\psi_{t}^{1}-\lambda_{t}=0 \\
\psi_{t}^{2}+\psi_{t}^{3}-\lambda_{t}=0 \\
\delta^{t} U_{2}^{\prime}+\psi_{t}^{3}-\lambda_{t}=0
\end{array}\right.
$$

We mention that the parameter $\lambda$ represents the Lagrange multiplier associated with the macroeconomic equilibrium condition (48).

From relations (50)-(53), we obtain

$$
\left\{\begin{array}{l}
\psi_{t}^{1}=\lambda_{t} \\
\psi_{t}^{2}=\lambda_{t}-\psi_{t}^{3} \\
\psi_{t}^{2}=\psi_{t}^{1}-\psi_{t}^{3}
\end{array}\right.
$$

It is interesting to remark that, as follows from (51) and (52), the value of the dual variable $\psi^{1}$, associated with private capital, is equal, at each time period, to the value of the Lagrange multiplier $\lambda$, and the dual variable $\psi^{3}$, associated with public debt, is equal to the difference of the dual variables associates to the two types of capital stock.

The dynamic equations for the dual variables are

$$
\left\{\begin{array}{l}
\psi_{t-1}^{1}=(1-\mu) \psi_{t}^{1}-\tau f_{1}^{\prime} \psi_{t}^{3}+\lambda_{t} f^{\prime} \\
\psi_{t-1}^{2}=(1-\mu) \psi_{t}^{2}-\tau f_{2}^{\prime} \psi_{t}^{3}+\lambda_{t} f^{\prime} \\
\psi_{t-1}^{3}=\left[1+(1-\tau) r_{t}\right] \psi_{t}^{3}
\end{array}\right.
$$

Taking into account relationships (54)-(56), the dynamic equations (57) and (58) can be rewritten as:

$\psi_{t-1}^{1}=\left(1-\mu+f_{1}^{\prime}\right) \psi_{t}^{1}-\tau f_{1}^{\prime} \psi_{t}^{3}$

$\psi_{t-1}^{2}=\left(1-\mu+f_{2}^{\prime}\right) \psi_{t}^{1}-\tau f_{2}^{\prime} \psi_{t}^{3}$

At the same time, taking into account formulae (54)-(56), the optimality conditions (50) and (53) can be rewritten as

$\delta^{t} U_{1}^{\prime}=\psi_{t}^{1}$

$\delta^{t} U_{2}^{\prime}=\psi_{t}^{2}$

Taking into account the form of the utility function, from (62) and (63) it follows 
$\frac{U_{1}^{\prime}}{U_{2}^{\prime}}=\frac{1-\gamma}{\gamma} \cdot \frac{s_{t}}{C_{t}}=\frac{\psi_{t}^{1}}{\psi_{t}^{2}}$

and

$\psi_{t}^{2}=\frac{\gamma}{1-\gamma} \cdot \frac{c_{t}}{s_{t}} \cdot \psi_{t}^{1}$

respectively.

Taking into account that

$\psi_{t}^{3}=\psi_{t}^{1}-\psi_{t}^{2}$

it follows

$\psi_{t}^{3}=\left(1-\frac{\gamma}{1-\gamma} \cdot \frac{c_{t}}{s_{t}}\right) \psi_{t}^{1}$

From the dynamic equations of the dual variables we obtain

$\psi_{t-1}^{1}-(1-\mu) \psi_{t}^{1}=\left(\psi_{t}^{1}-\tau \psi_{t}^{3}\right) f_{1}^{\prime}$

$\psi_{t-1}^{2}-(1-\mu) \psi_{t}^{2}=\left(\psi_{t}^{1}-\tau \psi_{t}^{3}\right) f_{2}^{\prime}$

and

$\frac{\psi_{t-1}^{1}-(1-\mu) \psi_{t}^{1}}{\psi_{t-1}^{2}-(1-\mu) \psi_{t}^{2}}=\frac{f_{1}^{\prime}}{f_{2}^{\prime}}=\frac{\alpha}{\beta} \cdot \frac{g_{t}}{k_{t}}$

which can be rewritten as

$\psi_{t-1}^{1}-\frac{\alpha}{\beta} \cdot \frac{g_{t}}{k_{t}} \psi_{t-1}^{2}=(1-\mu)\left(\psi_{t}^{1}-\frac{\alpha}{\beta} \cdot \frac{g_{t}}{k_{t}} \psi_{t}^{2}\right)$

We mention that the formulae obtained indicate that the dual variables $\psi^{2}$ and $\psi^{3}$ can be expressed as functions of the dual variable $\psi^{1}$.

In what follows, we shall assume again that the ratio between private and public consumption is constant, i.e.

$\frac{C_{t}}{S_{t}}=\frac{C_{t-1}}{S_{t-1}}=\varepsilon$ 
With this assumption, the optimal value of the interest rate is

$r_{t}=f_{1}^{\prime}+\frac{\tau}{1-\tau} \cdot \frac{\gamma}{1-\gamma} \varepsilon f^{\prime}-\frac{\mu}{1-\tau}$

Comparing formula (73) with formula (15) derived for the optimal value of the interest rate in the case of the model discussed in section 2, we can see that the two values do not coincide; the optimal value of the interest rate is larger for the present model.

In what follows, we show that the optimal growth rate of consumption is also larger in the present model than in the model of the consumer-producer agent studied in section 2 .

Indeed, based on the relationships derived above, we obtain the following dynamic equation for the dual variable $\psi^{1}$

$\psi_{t-1}^{1}=\left[1-\mu+(1-\tau) f_{1}^{\prime}+\tau \frac{\gamma}{1-\gamma} \varepsilon f_{1}^{\prime}\right] \psi_{t}^{1}$

It can be rewritten as

$q_{t-1}^{1}=\delta\left[1-\mu+(1-\tau) f_{1}^{\prime}+\tau \frac{\gamma}{1-\gamma} \varepsilon f_{1}^{\prime}\right] q_{t}^{1}$

where

$q_{t}^{1}=\frac{\psi_{t}^{1}}{\delta^{t}}$

Using optimality condition (62), which can be rewritten as

$U_{1}^{\prime}=q^{1}$

we obtain

$\frac{c_{t}}{c_{t-1}}=\left[\delta\left[1-\mu+(1-\tau) f_{1}^{\prime}+\tau \frac{\gamma}{1-\gamma} \varepsilon f_{1}^{\prime}\right]\right]^{\frac{1}{v}}$

Comparison of formulae (78) and (24) justifies the assertion made above, namely that the optimal growth rate of consumption is larger for this model than for the previous one.

Finally, we show that, for the present model, there is a well-defined relationship between the indicator $\varepsilon$, which reflects the ratio between private and public consumption, and the indicator $\theta$, which reflects the ratio between public and private capital.

Indeed, from relations (65) and (71) it follows 
$\psi_{t-1}^{1}-\frac{\alpha}{\beta} \cdot \frac{g_{t}}{k_{t}} \cdot \frac{\gamma}{1-\gamma} \varepsilon \psi_{t-1}^{1}=(1-\mu)\left[\psi_{t}^{1}-\frac{\alpha}{\beta} \cdot \frac{g_{t}}{k_{t}} \cdot \frac{\gamma}{1-\gamma} \cdot \frac{C_{t}}{S_{t}} \psi_{t}^{1}\right]$

and

$\left[1-\frac{\alpha}{\beta} \cdot \frac{g_{t}}{k_{t}} \cdot \frac{\gamma}{1-\gamma} \cdot \varepsilon\right] \psi_{t-1}^{1}=(1-\mu)\left[1-\frac{\alpha}{\beta} \cdot \frac{g_{t}}{k_{t}} \cdot \frac{\gamma}{1-\gamma} \cdot \varepsilon\right] \psi_{t}^{1}$

respectively.

From (80), we obtain

$\left[1-\frac{\alpha}{\beta} \cdot \frac{g_{t}}{k_{t}} \cdot \frac{\gamma}{1-\gamma} \cdot \varepsilon\right]\left[\psi_{t-1}^{1}-(1-\mu) \psi_{t}^{1}\right]=0$

Using the notations already introduced, it follows

$\theta=\frac{\beta}{\alpha} \frac{1-\gamma}{\gamma} \varepsilon$

In the special case when

$\varepsilon=\frac{\gamma}{1-\gamma}$

We obtain

$\theta=\frac{\beta}{\alpha}$

This means that, if the ratio $\varepsilon$ between private and public consumption is equal to the ratio of elasticity coefficients in the utility function, then the ratio between private and public capital becomes equal to the ratio between the elasticity coefficients in the macroeconomic production function.

In this case, formula (78), which gives the growth rate of consumption, becomes aimed

$\frac{C_{t}}{c_{t-1}}=\left[\delta\left(1-\mu+f^{\prime}\right)\right]^{\frac{1}{v}}$

It can be seen that, in this case, the growth rate of consumption is independent of the tax rate.

We think that this conclusion is remarkable; in fact, it can be found empirically formulated in several ways in the relevant literature. In other words, we proved that, in 
the case when the ratio between private and public capital is equal to the ratio of elasticity coefficients in the utility function, then, necessarily, the ratio of public and private capital stock is equal to the ratio of elasticity coefficients in the production function. Moreover, in this case, the growth rate of the economy does not depend on the tax rate set by the government.

\section{Concluding remarks}

The impact of public capital and of public expenditure on economic growth remains one of the important issues in macroeconomics.

In this paper, we formulated two dynamic models , aimed at studying the impact of fiscal policies on the process of economic growth.

The first model refers to the way in which a consumer-producer agent optimizes its welfare in the case when the stock of public capital, government spending, as well as the tax rate are exogenous to him. For this model, we also study the steady-state conditions, when the public debt vanishes.

The second model analyzed refers to the fiscal policy of a "benevolent" government. We show that the optimal interest rate, as well as the growth rate of consumption are larger than in the case of the first model.

We also show that, with the additional assumption that the ratio between private and public capital is equal to the ratio of elasticity coefficients in the utility function, the growth rate of the economy does not depend on the tax rate set by the government and the ratio of public and private capital stock must be equal to the ratio of elasticity coefficients in the macroeconomic production function. 


\section{Bibliography}

1. Afonso, Antonio et al (2005), Quality of Public Finances and Growth, European Central Bank working paper series no.438

2. Altar, M and Samuel, J. (2003) Fiscal and Monetary Policies and Economic Growth, paper presented at the $56^{\text {th }}$ International Atlantic Economic Conference, Quebec, Canada

3. Altar, M and Samuel, J. (2004) Fiscal Policy, Public Capital and Economic Growth, paper presented at the $58^{\text {th }}$ International Atlantic Economic Conference, Chicago, Illinois

4. Arrow, K.J. and Kurz, M. (1970), Public Investment, the Rate of Return and Optimal Fiscal Policy, Baltimore, MD: John Hopkins University Press;

5. Aschauer, D.A. (1988), The Equilibrium Approach to Fiscal Policy, Journal of Money, Credit, and Banking, vol. 20, pp. 41-62

6. Aschauer D.A. (1989a) Is Public Expenditure Productive?, Journal of Monetary Economics, vol. 23, pp. 177-200

7. Aschauer D.A. (1989b) Does public capital crowd out private capital?, Journal of Monetary Economics, vol.24, pp. 171-88

8. Aschauer D.A. and Greenwood, J. (1985). Macroeconomic Effects of Fiscal Policy, CarnegieRochester Conference Series on Public Policy, vol. 23, pp. 91-138

9. Barro R.J., (1989) The neoclassical approach to fiscal policy, Modern Business Cycle Theory (ed. R.J.Barro), pp. 178-235, Cambridge MA.; Harvard University Press

10. Barro R.J. (1990) Government Spending in a simple model of endogenous growth, Journal of Political Economy, vol. 98, pp-S103-25

11. Barro R. J. and Sata-i-Martin, X. (1995) Economic Growth, New York, McGraw-Hill

12. Baxter, M. and King R.G. (1993) Fiscal Policy in general equilibrium, American Economic Review, vol.83, pp 315-34

13. Chamley C. (1986) Optimal Taxation of Capital in General Equilibrium with Infinite Lives, Econometrica, vol.54, pp 607-22

14. Edwards J.H.Y. (1990) Congestion Function specification and the publicness of local public goods, Journal of Urban Economics, vol.27, pp 80-96

15. Fisher, W.H. and Turnovsky, S.J. (1998) Public Investment, Congestion, and Private Capital Accumulation, The Economic Journal, vol 108. pp. 399-413

16. Futagami, K.Y., Morita Y and Shibata A. (1993) Dynamic Analysis of an endogenous growth model with public capital, Scandinavian Journal of Economics, vol.95, pp.607-25

17. Ghosh, S, and Nolan, C (2004), The Impact of Simple Fiscal Rules in Growth Models with Public Goods and Congestion, working paper, University of St.Andrews

18. Glomm G. and Ravikumar, B. (1994) Public Investment in infrastructure in a simple growth model, Journal of Economic Dynamics and Control, vol.18, pp. 1173-87

19. Gramlich E.M. (1994). Infrastructure investment: a review essay, Journal of Economic Literature, vol. 32, pp. 1176-96

20. Judd, K.L. (1985) Redistributive Taxation in a simple perfect foresight model, Journal of Public Economics, vol. 28, pp.59-93

21. Lynde C. and Richmond J. (1993) Public Capital and Long-Run costs in UK Manufacturing, Economic Journal, vol. 103, pp. 880-93

22. Romer P.M. (1986) Increasing Returns and Long-Run Growth, Journal of Political Economy, vol. 94, pp.1002-37

23. Tanzi, V. (2004) The Economic Role of the State in the XXI Century, mimeo, paper prepared for presentation at a seminar at Politeia, London

24. Tanzi, V. and Schuknecht, L. (2003) Public Finances and Economic Growth in European Countries in Fosterin Economic Growth in Europe, conference volume of the $31^{\text {st }}$ Economics Conference of the Oestereichische Nationalbank, Vienna, pp. 178-196

25. Thompson E.A. (1976) Taxation and National Defense, Journal of Political Economy, vol.82, pp.755-82 
26. Turnovsky, S.J. (1995) Methods of Macroeconomic Dynamics, Cambridge, MA; MIT Press.

27. Turnovsky S.J. and Fisher W.H. (1995) The Composition of government expenditure and its consequences for macroeconomic performance, Journal of Economic Dynamics and Control, vol.19, pp. 747-86 